\title{
EDITORIAL
}

\section{Secondary malignancies after transplantation for aplastic} \section{anemia}

(c) The Author(s), under exclusive licence to Springer Nature Limited 2021

Bone Marrow Transplantation (2021) 56:2324-2325; https://doi.org/10.1038/s41409-021-01400-z

Aplastic anemia (AA) is a rare non-malignant hematological disorder for which allogeneic transplantation has been proved to be a curative option almost 50 years ago [1]. As a nonmalignant disease AA is the archetype of diseases in which GvL is not mandatory but where acute and chronic do arm! Early attempts for transplantation in AA were associated with an increased risk of rejection due to the recipients' alloimmunization. Attempts to reduce alloimmunization-induced rejection included donor buffy coat injection (that increased GVHD risk) or use of irradiation (that both increased chronic GVHD and risk of secondary malignancies). In two seminal papers the Seattle group provided formal evidence on what remains the gold standard of transplantation in patients with AA transplanted from HLAidentical sibling donors: the use of cyclophosphamide (Cy) and ATG as conditioning regimen [2] and the combination of cyclosporine (CSA) with methotrexate (MTX) for prevention of acute GVHD [3].

Using Cy-ATG as a conditioning regimen and CSA + MTX as GVHD prophylaxis in patients with AA transplanted from related donors using a bone marrow graft, the expected long-term (20year) survival rate is in the $90 \%$ range ([4], and Vo et al. this issue) nearly reaching expected survival in the general population [5]. However, we are still faced with an unneeded and too high a rate of chronic GVHD (in the $20 \%$ range) and there is few evidence that newer conditioning regimens that include fludarabine can decrease this incidence [6].

In this issue Vo et al. report another disappointing late effect of transplantation in AA, i.e., secondary malignancies. The obvious strength of this very well-analyzed cohort is the very long-term results (median follow-up exceeding 25 years) that authors from the Seattle group can provide. Among 329 patients with AA given HLA-related marrow graft, 53 cancers occurred in 46 patients, 42 had solid tumors, and 4 hematological malignancies. The 26-year cumulative incidence of cancer was $11 \%$, representing a twofold increased rate relative to the USA general population. Of the 42 solid tumors half were non-melanoma skin cancers and 7 epidermoid oropharyngeal carcinomas. Both non-melanoma skin cancers and head and neck tumors showed significant association with chronic GVHD. The overall type of solid tumors fit with what has been previously in large series that included different malignant diseases $[7,8]$ but only two were restricted to patients with $\mathrm{AA}[9,10]$. Of note, patients with congenital $A A$, especially those with Fanconi's anemia who have an inherited propensity of developing cancers that is increased by transplantation through GVHD and irradiation-based conditioning (reviewed in [7]), were excluded from the current Seattle group analysis.

Non-melanoma skin cancers include mainly basal cell carcinoma (BCC) and squamous cell carcinoma (SCC). Tumor subtype (BCC vs. SCC) is not provided in the present analysis. An earlier analysis of the Seattle's group data, however, previously reported older age, irradiation (for BCC), light-skinned (for BCC), and chronic GVHD as risk factors for non-melanoma skin cancers after hematopoietic cell transplantation [11]. These factors have been confirmed in other studies (reviewed in [12]). Finally, a recent case-control study found an increased risk of both SCC and BCC in photodamaged skin in transplant recipients [13]. These data deserve two comments; (1) there is probably under-reporting of skin SCC and BCC in long-term survivors especially as they age; (2) these cancers are easily amenable to early clinical detection especially in patients with previous chronic GVHD. Furthermore, sun-blocking creams represent efficient prophylaxis, especially in photodamaged skin.

Two HCV-infected patients developed liver carcinoma as previously reported [14]. Fortunately, due to the disappearance of HCV-infected blood products and efficient anti-viral treatment in long-term infected individuals, we expect these lethal disorders to no longer be of concern. Epidermoid oropharyngeal carcinomas were the second most frequent tumors. These tumors with an overall poor prognosis post-transplant [15] have been strongly linked to previous chronic GVHD [16]. Here again regular specialized follow-up of patients with previous oral chronic GVHD is mandatory as well as avoidance of tobacco and excessive alcohol consumption. Finally, other various cancers in long-term survivors in Vo et al. cohort occurred. One deserved further comment, i.e., breast cancers (2.5 increased standardized incidence). A previous joined EBMT/Seattle analysis found that increased risk of breast cancer was associated with irradiationbased conditioning [17] that is not the case here for patients with AA. Since breast cancers tend to develop very late post-transplant [17], there is a note of caution for life-long surveillance in women who have been transplanted regardless of the conditioning regimen.

Finally, three hematological malignancies are reported in the Vo et al series: one host-derived-ALL and two donor-derived MDS, as previously discussed [18]. These two later donor-derived MDS cases raise fundamental questions on oncogenesis. The mechanisms of donor-derived hematological malignancies are poorly understood, yet. However, description in the past few years of clonal hematopoiesis with of indeterminate potential (CHIP) in aged individuals [19] raised the hypothesis that donor hematopoiesis in the context of transplantation might be prone to CHIP and later evolution to MDS because of stressed hematopoiesis in the context of transplantation.

In conclusion, the study by Vo and coworkers provides the most useful information for the long-term follow-up of patients transplanted for AA. It reinforces the critical need for life-long surveillance of late effects and obviously should stimulate such studies on late effect post-transplantation, in particular on late effect post transplantation from unrelated donor in patients with AA for whom we almost completely lack data 
Gérard Socié $(\mathbb{D})^{1,2 \otimes}$ and Régis Peffault de Latour (iD ${ }^{2}$ ${ }^{1}$ Université de Paris, INSERM U976, Paris, France. ${ }^{2}$ Hematology Transplantation, AP-HP Saint Louis Hôpital, Paris, France.

凶email: gerard.socie@aphp.fr

\section{REFERENCES}

1. Thomas ED, Storb R, Fefer A, Slichter SJ, Bryant JI, Buckner CD, et al. Aplastic anaemia treated by marrow transplantation. Lancet Lond Engl. 1972;1:284-9.

2. Storb R, Etzioni R, Anasetti C, Appelbaum FR, Buckner CD, Bensinger W, et al. Cyclophosphamide combined with antithymocyte globulin in preparation for allogeneic marrow transplants in patients with aplastic anemia. Blood. 1994;84:941-9.

3. Storb R, Weiden PL, Schroeder ML, Graham TC, Lerner KG, Thomas ED. Marrow grafts between canine litter-mates homozygous or heterozygous for lymphocytedefined histocompatibility antigens. Transplantation. 1976;21:299-306.

4. Ades L, Mary J-Y, Robin M, Ferry C, Porcher R, Esperou H, et al. Long-term outcome after bone marrow transplantation for severe aplastic anemia. Blood. 2004;103:2490-7.

5. Wingard JR, Majhail NS, Brazauskas R, Wang Z, Sobocinski KA, Jacobsohn D, et al. Long-term survival and late deaths after allogeneic hematopoietic cell transplantation. J Clin Oncol. 2011;29:2230-9.

6. Bejanyan N, Kim S, Hebert KM, Kekre N, Abdel-Azim H, Ahmed I, et al. Choice of conditioning regimens for bone marrow transplantation in severe aplastic anemia. Blood Adv. 2019;3:3123-31.

7. Galy AS del, Michonneau D, Socié G. Second malignancies. In: Blood and marrow transplantation long term management: Survivorship after transplant. Savani BN Tichelli A, editors. John Wiley. Second Edition. Chichester, West Sussex, UK: John Wiley \& Sons, Ltd; 2021, pp 101-11.

8. Curtis RE, Rowlings PA, Deeg HJ, Shriner DA, Socíe G, Travis LB, et al. Solid cancers after bone marrow transplantation. N. Engl J Med. 1997;336:897-904.

9. Deeg HJ, Socié G, Schoch G, Henry-Amar M, Witherspoon RP, Devergie A, et al. Malignancies after marrow transplantation for aplastic anemia and fanconi anemia: a joint Seattle and Paris analysis of results in 700 patients. Blood. 1996;87:386-92.

10. Socié $G$, Henry-Amar $M$, Bacigalupo $A$, Hows J, Tichelli $A$, Ljungman $P$, et al. Malignant tumors occurring after treatment of aplastic anemia. European Bone Marrow Transplantation-Severe Aplastic Anaemia Working Party. N. Engl J Med. 1993;329:1152-7.

11. Leisenring W, Friedman DL, Flowers MED, Schwartz JL, Deeg HJ. Nonmelanoma skin and mucosal cancers after hematopoietic cell transplantation. J Clin Oncol J Am Soc Clin Oncol. 2006;24:1119-26.
12. DePry JL, Vyas R, Lazarus HM, Caimi PF, Gerstenblith MR, Bordeaux JS. Cutaneous Malignant Neoplasms in Hematopoietic Cell Transplant Recipients: A Systematic Review. JAMA Dermatol. 2015;151:775-82.

13. Scott JF, Brough KR, Grigoryan KV, Muzic JG, Kim GY, Conic RRZ, et al. Risk Factors for Keratinocyte Carcinoma in Recipients of Allogeneic Hematopoietic Cell Transplants. JAMA Dermatol. 2020;156:631-9.

14. Peffault de Latour R, Lévy V, Asselah T, Marcellin P, Scieux C, Adès L, et al. Longterm outcome of hepatitis $C$ infection after bone marrow transplantation. Blood. 2004;103:1618-24.

15. Tichelli A, Beohou E, Labopin M, Socié G, Rovó A, Badoglio M, et al. Evaluation of second solid cancers after hematopoietic stem cell transplantation in European patients. JAMA Oncol. 2019;5:229-35.

16. Curtis RE, Metayer C, Rizzo JD, Socié G, Sobocinski KA, Flowers MED, et al. Impact of chronic GVHD therapy on the development of squamous-cell cancers after hematopoietic stem-cell transplantation: an international case-control study. Blood. 2005;105:3802-11.

17. Friedman DL, Rovo A, Leisenring W, Locasciulli A, Flowers MED, Tichelli $A$, et al. Increased risk of breast cancer among survivors of allogeneic hematopoietic cell transplantation: a report from the FHCRC and the EBMT-Late Effect Working Party. Blood. 2008;111:939-44.

18. Engel N, Rovo A, Badoglio M, Labopin M, Basak GW, Beguin Y, et al. European experience and risk factor analysis of donor cell-derived leukaemias/MDS following haematopoietic cell transplantation. Leukemia. 2019;33:508-17.

19. Steensma DP, Bejar R, Jaiswal S, Lindsley RC, Sekeres MA, Hasserjian RP, et al. Clonal hematopoiesis of indeterminate potential and its distinction from myelodysplastic syndromes. Blood. 2015;126:9-16.

\section{COMPETING INTERESTS}

The authors declare no competing interests.

\section{ADDITIONAL INFORMATION}

Correspondence and requests for materials should be addressed to G.S.

Reprints and permission information is available at http://www.nature.com/ reprints

Publisher's note Springer Nature remains neutral with regard to jurisdictional claims in published maps and institutional affiliations. 